\title{
Women's experiences of formula feeding their infants: an interpretative phenomenological study
}

Kin Yan Sze*, Zenobia Chung Yee Chan, Vico Chung Lim Chiang

School of Nursing, The Hong Kong Polytechnic University, Hong Kong, China

Received: 18 August 2017; Accepted: 19 September 2017; Published: 20 March 2018

Abstract: Objective: This study aimed to explore the experiences of women in the process of formula feeding their infants. The World Health Organization has emphasized the importance of breastfeeding for infant health. After decades of breastfeeding promotions, breastfeeding rates in Hong Kong have been rising consistently; however, the low continuation rate is alarming. This study explores women's experiences with formula feeding their infants, including factors affecting their decision to do so.

Methods: A qualitative approach using an interpretative phenomenological analysis (IPA) was adopted as the study design. Data were collected from 2014 to 2015 through individual in-depth unstructured interviews with 16 women, conducted between 3 and 12 months after the birth of their infant. Data were analyzed using IPA.

Results: Three main themes emerged as follows: (1) self-struggle, with the subthemes of feeling like a milk cow and feeling trapped; (2) family conflict, with the subtheme of sharing the spotlight; and (3) interpersonal tensions, with the subthemes of embarrassment, staring, and innocence. Many mothers suffered various stressors and frustrations during breastfeeding. These findings suggest a number of pertinent areas that need to be considered in preparing an infant feeding campaign.

Conclusions: The findings of this study reinforce our knowledge of women's struggles with multiple sources of pressure, such as career demands, childcare demands, and family life after giving birth. All mothers should be given assistance in making informed decisions about the optimal approach to feeding their babies given their individual situation and be provided with support to pursue their chosen feeding method.

Keywords: formula feeding • infant feeding • breastfeeding • feeding decision • experience $\bullet$ Qualitative $\bullet$ interpretative phenomenological analysis $\bullet$ women $\bullet$ education $\bullet$ support $\bullet$ nurse $\bullet$ nursing

(c) Shanxi Medical Periodical Press.

\section{Introduction}

The medical community and public health organizations, such as the World Health Organization (WHO), have repeatedly emphasized the benefits of breastfeeding, including a reduced risk of developing obesity-related diseases and allergies, for infant health. ${ }^{1-15}$ After decades of breastfeeding promotions, breastfeeding rates in Hong Kong have risen consistently, with initiation rates of $>85 \%$; however, the low continuation rate of exclusive breastfeeding, with only $31 \%$ of infants still breastfeeding at 1 month, and the widespread use of infant formula are alarming. $4-6,11,16,17$ This rate is far below the WHO recommendation that infants should be fed exclusively with breast milk until the age of 6 months. ${ }^{14}$ An even greater concern is the fact that the breastfeeding rate in Hong Kong decreases significantly once the infant has been discharged and this rate is among the lowest in the world. ${ }^{6}$ There have been few studies on the reasons why many Hong Kong mothers formula feed their babies. From a public health perspective, it is important to understand these issues so that health pro- 
fessionals and policy makers can better support the feeding decisions of mothers.

Five studies have explored women's experiences of bottle-feeding with reference to various emotions. , $^{9,18-22}$ Other studies have explored the barriers that women encounter when attempting to formula feed their infants. ${ }^{23-25}$

When mothers decide to formula feed their infants, they experience a range of emotions, particularly if they had decided prior to delivery to breastfeed the infant. These emotions include guilt, ${ }^{18-21}$ failure, and uncertainty. ${ }^{20}$ In addition, mothers often feel angry about the excessive pressure they face to breastfeed. ${ }^{20,22}$ Although the experiences of women who breastfeed their babies have been studied extensively and have been widely reported in the literature, ${ }^{1,2,4,6,10-13,15}$ most of this research has focused on women's rationale for not breastfeeding as a means to develop interventions to promote breastfeeding. Moreover, only a limited number of studies have investigated the factors associated with the decision of Chinese mothers to formula feed. ${ }^{25}$

Another common finding in previous research is that many mothers who bottle-fed their babies reported receiving inadequate information from health-care providers. ${ }^{23}$ This lack of information has resulted in a number of worrying issues. Bolling et al. ${ }^{26}$ have reported that hygiene and safety recommendations are often not followed in preparing formula. Parents often change the brand of the formula milk that they use because of regurgitation issues, when it is possible that the actual reason for this symptom is not intolerance but overfeeding. Although health-care providers are the most frequently cited source of information, research shows women to be more likely to initiate discussions about infant feeding with family and friends, probably because healthcare providers are perceived as not being supportive of bottle-feeding. ${ }^{23}$ Furthermore, formula milk is promoted in shops to the general public and free samples are given to mothers. Mothers often feel confused by these promotions, leading them to believe that formula milk is an appropriate substitute for breast milk. ${ }^{24,25,27}$ This suggests that there is a gap between the actual experiences of women in feeding their babies and the professional practice of promoting breastfeeding.

\section{Methods}

\subsection{Research questions}

There were two main research questions in this study as follows: (1) What experiences do mothers have with formula feeding? (2) How do mothers make the decision to formula feed?

\subsection{Design}

Interpretative phenomenological analysis (IPA) was used as the methodological approach in this study. ${ }^{28,29}$ IPA involves analyzing how individuals make sense of their experiences and actively engage in interpreting the events, objects, and people in their lives. It requires the interviewer to be reflexive and to realize that exploring the participants' meanings is an interpretative role. ${ }^{30,31}$ IPA is based on the fundamental principles of phenomenology, hermeneutics, and idiography. It integrates ideas from phenomenology and hermeneutics. The result is a method that is descriptive on the one hand, because it is concerned with how things appear and with letting things speak for themselves, and interpretative on the other because it recognizes that there is no such thing as a noninterpreted phenomenon. IPA also relies on idiographic analysis, which means that it examines objects of interest in considerable detail, thus requiring relatively small sample sizes. ${ }^{28,32}$ This study used IPA to focus on how mothers perceive and understand their formula-feeding experiences.

\subsection{Participants}

A purposive sample of women who had given birth in any Hong Kong hospital was recruited to ensure that participants with knowledge of formula feeding would be selected. Purposive sampling is a type of nonprobability sampling that is commonly used in qualitative research, whereby the sample is selected on the basis of predefined criteria. ${ }^{33}$ Participant selection in this study was guided by the following inclusion criteria: (1) women with a child <12 months of age; (2) postpartum women who speak Cantonese, which is the Chinese dialect most commonly spoken in Hong Kong, ${ }^{34}$ or English; and (3) women who initiated formula feeding at the birth of their youngest baby or initiated breastfeeding at birth but changed to formula feeding before the age of 6 months. The original plan was to interview mothers who had never breastfed their infant, but it was difficult to recruit an adequate number of such participants. Therefore, the scope of eligibility was widened to include women who might have breastfed their infant in the past, but who were exclusively formula feeding their infant by the time of the interview. Women who met one or both of the following criteria were excluded from taking part in the study: (1) mothers <18 years of age; and (2) mothers of infants who require complicated care, such as infants with serious health or developmental problems that might severely affect the process of breastfeeding. The justification for the second criterion for exclusion is that a mother's decision on how to feed her infant could 
well be affected if her infant has a complicated health condition.

\subsection{Data collection}

Data were collected between July 2014 and September 2015. The primary concerns of IPA are the details of individual experiences and quality rather than quantity. Accordingly, IPA studies usually benefit from a concentrated focus on a small number of cases. ${ }^{35}$ Morse $^{36}$ suggested that at least six informants be recruited for a phenomenological study, whereas Smith ${ }^{37}$ recommended between five and ten participants. The sample sizes in published IPA studies have ranged from one to fifteen participants. ${ }^{28}$ Finally, 16 women met the criteria for inclusion and were recruited to take part in this study. Data were collected until saturation was reached.

An unstructured interview was conducted with each participant in a location that suited her, such as a café. Data were collected between 3 and 12 months after the birth of the woman's youngest baby. The interviews ran from 25 minutes to just $>1$ hour in length. The unstructured interview approach constitutes an attempt to implement IPA's inductive epistemology to the fullest extent. ${ }^{35}$ Each interview had a single core question that did not direct the participants and permitted them to express whatever they felt was important, while at the same time maintaining a basic framework of inquiry. In this study, the initial opening question was as follows: Please tell me about your experiences of using formula milk to feed your baby. Prompts were used throughout the interviews to clarify questions or encourage responses. Demographic data on age range, age at marriage, level of education, and occupation were also collected from the participants.

\subsection{Ethical considerations}

Ethical approval was obtained for this study from the Hong Kong Polytechnic University prior to the commencement of the study, and the principles of nonmaleficence, autonomy, and confidentiality were strictly followed. An information sheet was provided to all eligible participants, and their written consent to participate in the study was obtained after they had been given an explanation of the purpose and procedure of the study. It was anticipated that the interviews might trigger an emotional response. If the participants were in emotional distress, the interviewer was prepared to terminate the interview and to refer the participant to a professional psychologist with the agreement of the participant. The participating women were assured that their participation was completely voluntary and that they could withdraw from the study at any time without penalty. All of the digital audiotaped data files were password protected, and pseudonyms were given to each participant. Their identities were protected by coded identifiers, and all information was kept strictly confidential. ${ }^{38}$ Participants' names and code numbers were kept in different locations. All research data will be discarded 2 years after the completion of the study, with any documents that could reveal the participants' identity to be shredded.

\subsection{Data analysis}

Data were analyzed using IPA, which is a method for analyzing qualitative data. ${ }^{28}$ The interviews were digitally recorded and transcribed verbatim. The initial stage of data analysis involved closely reading each transcript 10 times and listening to the audio recording. Notes were made in the left-hand margin of the transcript to reflect initial interpretations. The second stage of analysis involved reading the transcript in depth and making a note of anything important or interesting and/or of transitional significance. In the third stage, which involved clustering and organizing the emerging themes, connections were sought between those themes, and they were grouped together according to conceptual similarities, with each cluster assigned a descriptive label. The fourth stage involved searching for connections across emergent themes. Some themes were dropped at this stage if they did not fit well into the emerging structure or had a weak evidential basis. The fifth stage of data analysis involved systematically going through the transcripts of each one of the 16 participants and repeating the foregoing stages, and the sixth stage involved looking for patterns across the participants. The sequence was repeated many times until a level of data conceptualization that best captured the core themes in the entirety of the transcript texts was achieved. ${ }^{29}$

Rigor was enhanced by having two research supervisors review and countercheck the transcripts and emerging themes. Credibility, dependability, confirmability, and transferability were achieved through the use of audio recordings, field notes, participant quotes, and validations of findings by two supervisors, allowing the reader to verify the research process. ${ }^{39}$

\section{Results}

An analysis of the interview data resulted in three main themes as follows: (1) self-struggle, with subthemes of 


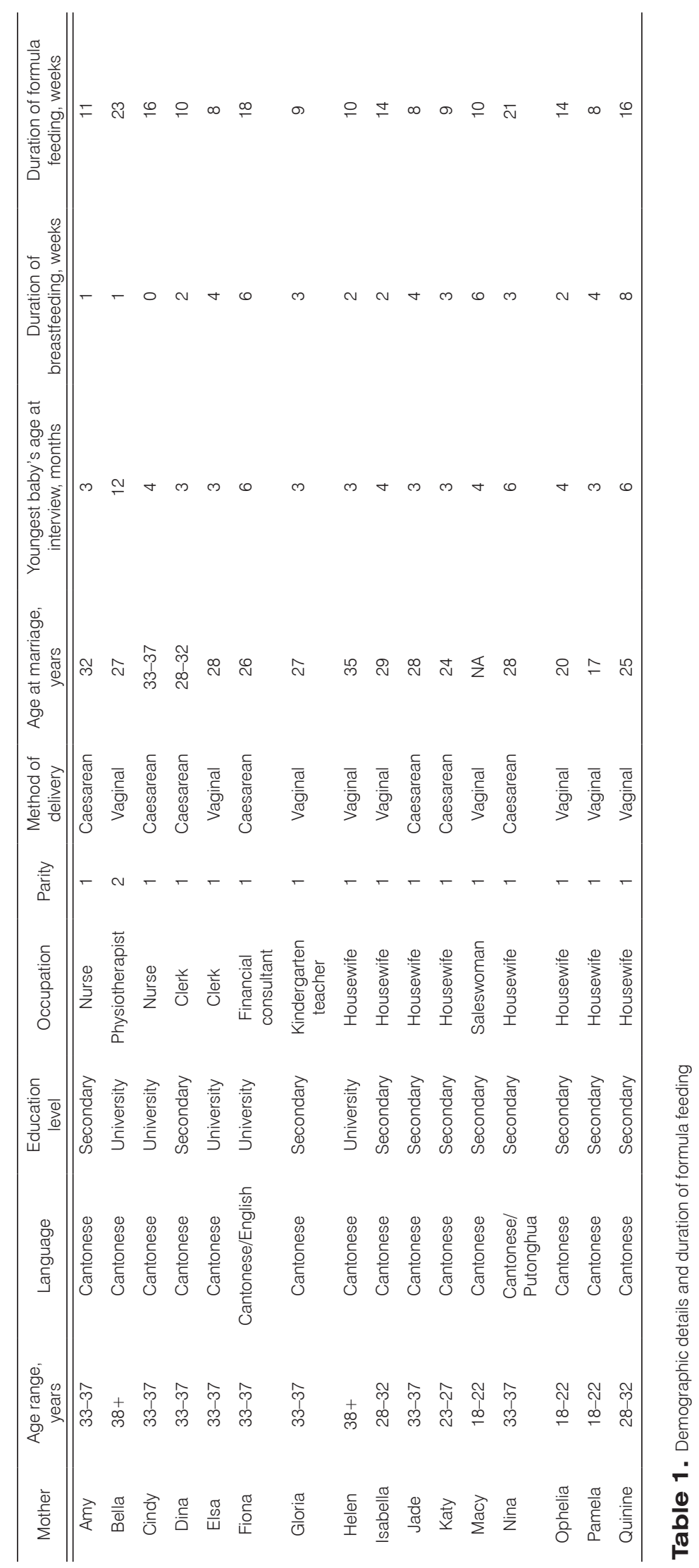


feeling like a milk cow and feeling trapped; (2) family conflict, with the subtheme of sharing the spotlight; and (3) interpersonal tensions, with the subthemes of embarrassment, staring, and innocence. Pauses in the quotes are indicated by ellipses (...). The 16 mothers who agreed to participate were aged between 18 and $38+$ years (age ranges rather than exact ages were collected for cultural reasons), had a parity of one to two, and were living with their husbands, with the exception of Macy, a single mother who was living with her parents. Eight mothers were employed and had returned to employment at the time of data collection, while the others were homemakers. All of the women had tried to breastfeed their youngest infant, with the exception of one, Cindy, who had never attempted to breastfeed. Fifteen mothers had shifted to bottle-feeding after experiencing difficulties with breastfeeding. Two of the 16 mothers decided to stop working after delivery. All participants were Chinese women from Hong Kong. The mothers' level of education, occupation, number of births, method of delivery, age at marriage, previous feeding experience, number of family members, and brand of formula milk selected are summarized in Table 1.

\subsection{Theme I - self-struggle}

In this theme, the experience of feeding their babies was a profound one for all of the mothers. The experience could fill them with happiness but also cause them to cry. Almost all of the participants described the feeding experience as unforgettable, and they told of the inner struggle that occurred during the process. Here, the concept of self-struggle refers to the struggle that occurs within an individual. It reflects an experience that occurs within a mother's mind. Such a struggle is psychological in nature, involving an individual's thoughts. ${ }^{40,41}$ The participating mothers knew that breastfeeding offered advantages to their babies, but for a variety of reasons they were unable to maintain the practice. Two subthemes are used to anchor the discussion of the mothers' feeding experience as follows: feeling like a milk cow and feeling trapped.

\subsubsection{A milk cow}

The participants reported numerous unpleasant breastfeeding experiences that fell under this subtheme. Fifteen mothers said that they had attempted, but failed, to continue breastfeeding their babies. Some said that they felt lonely and lacked help. They put all of their effort into producing milk, as illustrated by a mother's comments as follows:
During breastfeeding, I became a milk cow. I felt exhausted. I lost myself.... My baby sucked milk slowly.... I felt tired and was not even able to tidy myself up. I remember that I wore pajamas all day. I used up all my time for nonstop breastfeeding and diaper changing.... [Bella]

In addition to tying the mother to the infant, some mothers were unexpectedly forced to come to terms with a previously unimaginable dangerous situation, which Amy explained as follows:

... During breastfeeding, I needed to pump out my breast milk nonstop, but my baby would not take much of my milk. I needed to repeat and repeat the pumping process every two to three hours. I felt intolerable stress and nearly got a mental illness.... [Amy]

Like Amy and Bella, Ophelia also reported suffering from day and night nonstop breastfeeding as follows:

During breastfeeding, I slept very poorly ... I became a 24-hour full-time worker for breastfeeding.... I always woke up again and again.... I was worried and woke up easily. [Ophelia]

\subsubsection{Feeling trapped}

The women also felt trapped into continuously feeding their babies. Isabella and Jade described having to give up their former lives to concentrate on their babies and their needs. Isabella reported the following:

... I quit my job because I could not continuously breastfeed my baby and work at the same time.... I lost connection with my friends due to breastfeeding.... I could not meet my friends [any longer] since no one could wait until I finished breastfeeding my baby. I was trapped at home, and my world [was restricted to] feeding the baby. I also gave up... eating and trying different foods to prevent the quality of my breast milk from being affected. [lsabella]

Jade also felt trapped and felt that she had lost her freedom as follows:

I was trapped in the loop of breastfeeding... । [still] needed to feed my baby every two to three hours. My baby cried for 100 days. I locked myself up at home. My body did not belong to me only, [and] I needed to avoid eating foods that might cause an allergy. [Jade]

In contrast to their difficult breastfeeding experiences, switching to formula feeding was widely 
described as having lifted a heavy burden. The mothers expressed feelings of joy and said that life had become easier for them after they made the shift because they now had to spend less time feeding their babies. Amy, Bella, Cindy, Dina, and Gloria stated the following:

... I felt good ... I felt relaxed. I could control my life. My baby got enough milk and stopped [suffering from] diarrhea. [Amy]

My husband was able to bottle-feed my baby. I felt relief and happiness.... I could build up a good parent-child relationship during bottle-feeding [because it was] less time-consuming [than breastfeeding] and I could communicate with my baby. [Bella]

I felt happy to bottle-feed [my baby daughter]. Moreover, other family members were [eager] to help me during bottle-feeding, and [that] promoted our relationship. [Cindy]

My husband suggested [that I] switch to bottle-feeding so I would not need to pump breast milk at midnight. I could get more rest. [Dina]

Since I [started] bottle-feeding my baby, he gets enough milk, and his temper has improved. [Gloria]

The mothers' struggles were partly the result of their understanding that breastfeeding is still the best choice from the viewpoint of health-care professionals. ${ }^{14}$ Almost all of them had attempted to breastfeed but had failed for a variety of reasons. With the exception of Cindy, who had immediately begun formula feeding her baby, all of the others started out breastfeeding and then shifted to formula after a period of time. Most had to stop breastfeeding sooner than is considered ideal for babies, which led to self-struggle; they knew that breastfeeding was best, but simply could not sustain it.

\subsection{Theme II - family conflict}

Almost all of the mothers described a decline in their family life and relationships after commencing breastfeeding, with the emergence of family conflict. Conflicts are inevitable in life, preventable but completely unavoidable, and they are part of living in this world, especially conflicts that occur suddenly and cause great loss of life, damage, or hardship. ${ }^{42,43}$ In Hong Kong, as in other Confucian-based societies where great emphasis is placed on maintaining harmonious relationships with others, individuals are encouraged to sacrifice themselves for the benefit of the family. ${ }^{42}$ However, after a baby's birth, some women are expected to assume primary responsibility for much more than childrearing, which is shown by Macy's experience as follows:

I could not predict my life... I was scolded by my baby's father and grandmother. They forced me to stop breastfeeding and work again as soon as possible... I lost my personality and freedom. They [her boyfriend and his family] did not respect me. Finally, our relationship broke down. I gave up and went back home.... I felt tired and [thought that life was] very hard. [Macy]

Ophelia also talked about the occurrence of family conflicts once she began breastfeeding her baby as follows:

My mother-in-law rejected my choice [breastfeeding]. My husband was also fed by formula milk when he was a baby. She [her mother-in-law] did not know the advantages of breast milk and forced me to feed my baby with formula milk. I ignored her and continued breastfeeding, and this triggered a breakdown in relations. [Ophelia]

One participant expressed the view that women should support their families by earning an income and complying with their mother-in-law's opinions on childcare. Otherwise, women lose their value in the family and destroy family harmony. The foregoing is one example of how family conflict can occur. When such conflict is absent or alleviated, family members can be sources of emotional and practical support for mothers. However, family conflict makes breastfeeding much more difficult than it would otherwise be. In this case, Macy lost the support of her family, experienced the destruction of family harmony, and was not able to persist in breastfeeding her baby.

\subsubsection{Sharing the spotlight}

Within the larger theme of family conflict, the following subtheme was identified: sharing the spotlight. Some of the mothers discussed having to give up her former position in the family; Pamela is one such example, as follows:

\footnotetext{
After my baby was born, many relatives, even those who were not very close, visited us. They were all happy to visit my baby.... However, I was a little bit disappointed ... no one cared about me and my feelings. [Pamela]
}

When the whole family was celebrating the birth of the baby, the mothers also expected that their new 
needs and hard work in childcare would be acknowledged. In Pamela's case, she felt disappointed because no one understood her feelings, moreover, no one attempted to do so. Family conflict could have occurred unintentionally.

\subsection{Theme III - interpersonal tensions}

The participants in this study had experienced the transition from womanhood to motherhood. After their babies were born, many women returned to work. Dilemmas then emerged, as they were forced to struggle simultaneously with the pressures of work, baby care, and family life. Not every woman had the option of quitting her career. Interpersonal tensions refer to tension between individuals, whether they be coworkers, siblings, spouses, or neighbors. ${ }^{40,41}$

Three subthemes are used here to anchor the discussion on interpersonal tensions as follows: embarrassment, staring, and innocence.

\subsubsection{Embarrassment}

The mothers described feeling guilty or embarrassed about occupying shared office facilities. Amy and Isabella explained the following:

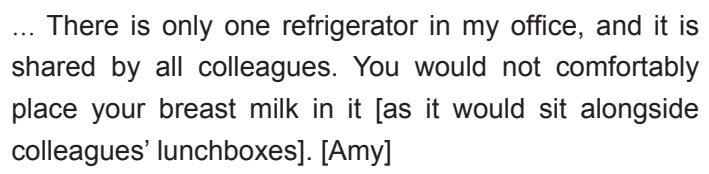
shared by all colleagues. You would not comfortably place your breast milk in it [as it would sit alongside colleagues' lunchboxes]. [Amy]

... There is a refrigerator; however, we also need to store our lunchboxes inside it. I was embarrassed when male colleagues saw my breast milk in the refrigerator.... [Isabella]

Once women return to work, interpersonal tensions occur frequently between mothers and their coworkers over the need of the former to make use of workplace facilities.

\subsubsection{Staring}

Many of the mothers said that they felt tense about the increased workload on others resulting from their absence. Once they have children, women try to fulfill the following two major roles in life: being a valued employee and being a good mother. In some instances, others in the workplace seem to doubt whether women can continue on as they did before giving birth. Isabella mentioned being stared at by her supervisor as follows:
... My supervisor stared at me [but] would not comment on my breastfeeding.... Usually, I had to finish my work before I could go to the toilet to pump out my breast milk. Otherwise, my supervisor and colleagues would criticize me, as I would need to leave for 30 minutes. I sustained a certain amount of pressure. If I wanted to keep my career, I needed to stop breastfeeding. [Isabella]

Fiona reported having the following similar experience:

Before I... pumped my breast milk, I had to arrange to finish my work first. I had to have good communication with my colleagues; otherwise, they would challenge my working ability. [Fiona]

At the same time, as they experienced these frustrations, the women also expected that their new needs and circumstances would be respectfully acknowledged. However, when they returned to work, they felt they were under unreasonable pressure.

\subsubsection{Innocence}

Most women in Hong Kong give birth in a hospital. The participating mothers discussed some of the disappointing experiences that they had had with doctors and nurses in trying to advocate for their own feeding method. Amy and Jade, for example, experienced great conflict with the necessity for health-care professionals to follow protocol and their concomitant refusal to listen to them and trust them, as follows:

... The health-care professionals did not accept my decision to switch to bottle-feeding. They blamed me and my husband. They only had one idea, which was that all mothers must breastfeed their babies. The midwife regarded me as a selfish and irresponsible mother. [Amy]

... Doctors and nurses told me that I was feeding my baby very well. However, after two days had passed, it was discovered that my baby was suffering from dehydration. I started to beg for formula milk as a supplement but was rejected by the nurses. I was trapped in the hospital, and no one was willing to help me. A breastfeeding promotion health-care team visited me, but they forced me to continue breastfeeding.... I felt helpless. Finally, I rejected medical advice and escaped to go home. [Jade]

Some of the mothers did not trust the nurses and/or questioned their ability, as Quinine's comments show: 
.. The nurses were not helpful. They had never been pregnant nor had they breastfed, so they knew nothing. They were all empty talk. [Quinine]

These examples show that the mothers had various experiences in the hospital and in the maternal care unit; they all acknowledged the limitations of health-care professionals when it came to giving breastfeeding advice.

\section{Discussion}

Previous research has established that many factors, such as knowledge about the feeding of infants, culture, as well as social and family support, influence the decision to begin and continue breastfeeding or formula feeding. ${ }^{24,27,44-47}$ Knowledge that breastfeeding is best for infants is widespread, even among mothers in Hong Kong who choose formula feeding. Women in this study, including mothers who were health professionals, were aware of the health benefits of breastfeeding; however, despite this knowledge, they intended only to breastfeed for a short initial period. They regarded breastfeeding as only something that they would attempt, while seeing formula feeding as the reliable backup. A key issue raised by mothers was the idea that breastfeeding was becoming the normal way to feed an infant in Hong Kong today; however, the barriers to doing so had not been eliminated. The women described how they were struggling, feeling frustrated, experiencing a sense of hopelessness, and not enjoying their role as a breastfeeding mother.

The findings appear to contradict those studies that describe the tendency of nurses working in maternal childcare to quickly support bottle-feeding. ${ }^{11,19,48,49}$ Increasing the knowledge and skills of midwives through extra training would seem to be an effective way to promote breastfeeding. Public hospitals are increasingly introducing breastfeeding-friendly practices. ${ }^{2,5,12,49,50}$ However, the mothers indicated that breastfeeding is being promoted too rigidly and in a way that overrides their freedom of choice. For many women, their goal in feeding their infant is to have a content and healthy baby. In contrast, women perceive that the goal for health professionals is the continuation of breastfeeding. These differing goals caused dissatisfaction with the communication from health professionals, which the mothers regarded as being "breastfeeding centered" rather than "mother centered". The need to discuss breastfeeding in an open-ended and supportive manner was not fully considered. After being discharged from hospital, mothers often feel lonely and helpless over the issue of breastfeeding. They cannot overcome their self-struggles, family conflicts, and interpersonal ten- sions, leading to the early initiation of formula feeding. Fathers, family members, coworkers, and even society at large share equal responsibility for the early initiation of formula feeding.

There was a strong belief that breastfeeding was inconvenient, tying the mother to the infant, demanding, and too time-consuming, while formula feeding was easier and more convenient. It is interesting to note that the mothers ignored the inconveniences of formula feeding, such as maintaining the hygiene of the feeding bottle and the difficulties of purchasing formula in Hong Kong, particularly some of the better-known brands. They made attempts to purchase milk powder in other parts of Hong Kong if necessary, rather than continue with breastfeeding.

\section{Conclusions}

Women see childbirth as a major life event, and most try their best to feed their babies well. Despite its advantages, breastfeeding is not the choice of every mother. The findings of this study reinforce our knowledge of women's struggles with multiple sources of pressure from career demands, childcare demands, and family lives after giving birth. A substantial proportion of women opt to formula feed, and their feeding choice should be respected. A lack of posthospital breastfeeding support, combined with a rigid approach to promoting breastfeeding, led the participating mothers to feel that breastfeeding was an impossible mission. The findings of this study have implications for the practice and promotion of breastfeeding, as well as for future research using IPA to investigate feeding practices and similar research topics.

\subsection{Implications}

The findings suggest a number of areas that need to be considered in planning an infant-feeding campaign. All mothers should receive help in making an informed decision about the optimal approach to feeding their babies given their individual situation and be provided with support to pursue their chosen feeding method. Fear of criticism from health-care professionals inhibits women from communicating and seeking help. Psychological assistance should also be provided. For example, the government or charitable organizations could facilitate an open discussion about the mother's expectations both after having given birth and upon returning to work, as well as offer other forms of support at the interface between leaving and returning to work. This support could include practical support in the form of baby care or psycho- 
logical help to reintegrate into the workplace. Women who feed their babies formula milk make up a substantial proportion of Hong Kong society. Hence, they must not be ignored. Not every woman chooses to breastfeed or is able to do so. Women must be supported when they make the difficult decision to initiate formula feeding early.

\subsection{Limitations}

This study had a number of limitations that should be noted. First, the sample was restricted to women alone.

\section{References}

1. Bai DL, Wu KM, Tarrant M. Association between intrapartum interventions and breastfeeding duration. J Midwifery Womens Health. 2013;58:25-32.

2. Ku CM, Chow SK. Factors influencing the practice of exclusive breastfeeding among Hong Kong Chinese women: a questionnaire survey. J Clin Nurs. 2010;19:2434-2445.

3. Larsen JS, Kronborg $H$. When breastfeeding is unsuccessful-mothers' experiences after giving up breastfeeding. Scand $J$ Caring Sci. 2013;27:848-856.

4. Lee WT, Wong E, Lui SS, Chan V, Lau J. Decision to breastfeed and early cessation of breastfeeding in infants below 6 months old-a population-based study of 3,204 infants in Hong Kong. Asia Pac J Clin Nutr. 2007;16:163-171.

5. Leung J. Current role of maternal and child health service. Med Bulletin. 2009;14:16-19.

6. Loke AY, Chan LK. Maternal breastfeeding self-efficacy and the breastfeeding behaviors of newborns in the practice of exclusive breastfeeding. $J$ Obstet Gynecol Neonatal Nurs. 2013;42:672-684.

7. McAndrew F, Thompson J, Fellows L, Large A, Speed M, Renfrew MJ. Infant Feeding Survey 2010. Leeds: Health and Social Care Information Centre; 2012.

8. Ngai FW, Chan SW, Holroyd E. Chinese primiparous women's experiences of early motherhood: factors affecting maternal role competence. J Clin Nurs. 2011;20:1481-1489.

9. Spencer RL, Greatrex-White S, Fraser DM. 'I thought it would keep them all quiet'. Women's experiences of breastfeeding as illusions of compliance: an interpretive phenomenological study. J Adv Nurs. 2015;71:1076-1086.

10. Tarrant M, Dodgson JE. Knowledge, attitudes, exposure, and future intentions of Hong Kong university
Hence, the experiences of fathers with regard to formula feeding need to be explored in a future study. Second, the data on formula feeding were self-reported by the participants and, thus, may be subject to recall bias. Finally, the study did not make any comparisons between mothers who breastfed and those who formula fed and, hence, did not examine the differences between the two groups.

\section{Conflicts of interest}

All contributing authors declare no conflicts of interest.

students toward infant feeding. J Obstet Gynecol Neonatal Nurs. 2007;36:243-254.

11. Tarrant M, Fong DY, Wu KM, et al. Breastfeeding and weaning practices among Hong Kong mothers: a prospective study. BMC Pregnancy Childbirth. 2010;10:27.

12. Tarrant M, Wu KM, Fong DY, et al. Impact of babyfriendly hospital practices on breastfeeding in Hong Kong. Birth. 2011;38:238-245.

13. Wang W, Lau Y, Chow A, Chan KS. Breast-feeding intention, initiation and duration among Hong Kong Chinese women: a prospective longitudinal study. Midwifery. 2014;30:678-687.

14. World Health Organization. Exclusive Breastfeeding for Six Months Best for Babies Everywhere. Geneva: WHO. Available at: http://www.who.int/ mediacentre/news/statements/2011/breastfeeding_ 20110115/en/. 2011. Accessed May 10, 2017.

15. Ying L. Breastfeeding intention among pregnant Hong Kong Chinese women. Matern Child Health J. 2010;14:790-798.

16. Hawkins SS, Stern AD, Baum CF, Gillman MW. Evaluating the impact of the Baby-Friendly Hospital Initiative on breast-feeding rates: a multi-state analysis. Public Health Nutr. 2015;18:189-197.

17. Lok KY, Bai DL, Tarrant M. Predictors of breastfeeding initiation in Hong Kong and Mainland China born mothers. BMC Pregnancy Childbirth. 2015;15:286.

18. Bailey C, Pain RH, Aarvold JE. A 'give it a go' breast-feeding culture and early cessation among low-income mothers. Midwifery. 2004;20:240-250.

19. Cloherty M, Alexander J, Holloway I. Supplementing breast-fed babies in the UK to protect their mothers from tiredness or distress. Midwifery. 2004;20:194-204. 
20. Lee E. Health, morality, and infant feeding: British mothers' experiences of formula milk use in the early weeks. Sociol Health IIIn. 2007;29:1075-1090.

21. Thomson G, Ebisch-Burton K, Flacking R. Shame if you do-shame if you don't: women's experiences of infant feeding. Matern Child Nutr. 2015;11:33-46.

22. Wirihana LA, Barnard A. Women's perceptions of their healthcare experience when they choose not to breastfeed. Women Birth. 2012;25:135-141.

23. Cairney P, Barbour R. A research study of sources of support for bottle feeding in new mothers. Community Pract. 2007;80:30-34.

24. Dodgson JE, Tarrant M, Thompson JT, Young B. An analysis of infant feeding content found within the Hong Kong print media. J Hum Lact. 2008;24:317-325.

25. Zhang K, Tang L, Wang H, Qiu L, Binns CW, Lee $\mathrm{AH}$. Why do mothers of young infants choose to formula feed in China? Perceptions of mothers and hospital staff. Int J Environ Res Public Health. 2015;12:4520-4532.

26. Bolling K, Grant C, Hamlyn B, Thornton A. Infant Feeding Survey 2005. London: The Information Centre for Health and Social Care; 2006.

27. Nelson EA, Chan CW, Yu CM. Breast milk substitutes in Hong Kong. J Paediatr Child Health. 2004;40:350-352.

28. Pietkiewicz I, Smith JA. A practical guide to using Interpretative Phenomenological Analysis in qualitative research psychology. CPPJ. 2014;20:7-14.

29. Smith JA. Qualitative Psychology: A Practical Guide to Research Methods. London: Sage; 2007.

30. Camic PM, Rhodes JE, Yardley LE. Qualitative Research in Psychology: Expanding Perspectives in Methodology and Design. Washington, DC: American Psychological Association; 2003.

31. Smith J, Osborne M. Interpretative phenomenological analysis. In: Smith JA, ed. Qualitative Psychology: A Practical Guide to Research Methods. London: Sage Publications; 2008:53-79.

32. Chan ZCY, Fung YL, Chien WT. Bracketing in phenomenology: only undertaken in the data collection and analysis process? Qual Report. 2013;18:1-9.

33. Watkins MP, Portney L. Foundations of Clinical Research: Applications to Practice. 3rd ed. Upper Saddle River, NJ: Prentice Hall; 2009.

34. Matthews S, Yip V. Cantonese: A Comprehensive Grammar. New York: Routledge; 2013.
35. Smith JA, Flowers P, Larkin M. Interpretative Phenomenological Analysis: Theory, Method and Research. London: Sage; 2009.

36. Morse JM. Designing funded qualitative research. In: Denzin NK, Lincoln YS, eds. Handbook of Qualitative Research. 2nd ed. Thousand Oaks, CA: Sage; 1994:220-235.

37. Smith JA. Reflecting on the development of interpretative phenomenological analysis and its contribution to qualitative research in psychology. Qual Res Psychol. 2004;1:39-54.

38. Ryan F, Coughlan M, Cronin P. Step-by-step guide to critiquing research. Part 2: qualitative research. Br J Nurs. 2007;16:738-744.

39. Lincoln YS, Guba EG. Establishing trustworthiness. In: Guba EG, ed. Naturalistic Inquiry. London: SAGE Publications; 1985:289-331.

40. Lewicki R, Barry B, Saunders D. Essentials of Negotiation. 6th ed. Columbus: McGraw-Hill Higher Education; 2015.

41. Day GE, Leggat SG. Leading and Managing Health Services: An Australasian Perspective. Port Melbourne: Cambridge University Press; 2015.

42. Lu L, Cooper C. Handbook of Research on WorkLife Balance in Asia. Cheltenham, UK: Edward Elgar Publishing; 2015.

43. Math SB, Nirmala MC, Moirangthem S, Kumar NC. Disaster management: mental health perspective. Indian J Psychol Med. 2015;37:261-271.

44. Bolton KA, Kremer P, Hesketh KD, Laws R, Campbell KJ. The Chinese-born immigrant infant feeding and growth hypothesis. BMC Public Health. 2016;16:1071.

45. Ludlow V, Newhook LA, Newhook JT, Bonia K, Goodridge JM, Twells L. How formula feeding mothers balance risks and define themselves as 'good mothers'. Health Risk Soc. 2012;14:291-306.

46. Nguyen TT, Withers M, Hajeebhoy N, Frongillo EA. Infant formula feeding at birth is common and inversely associated with subsequent breastfeeding behavior in Vietnam. $J$ Nutr. 2016;146:2102-2108.

47. Sung $M$, Hong $H$. The influence of risk perception on South Korean mothers' use of infant formula. Health Risk Soc. 2015;17:368-387.

48. Brown A, Raynor P, Lee M. Healthcare professionals' and mothers' perceptions of factors that influence decisions to breastfeed or formula feed infants: a comparative study. $J$ Adv Nurs. 2011;67:1993-2003. 
49. Tarrant M, Lok KY, Fong DY, et al. Effect of a hospital policy of not accepting free infant formula on in-hospital formula supplementation rates and breast-feeding duration. Public Health Nutr. 2015;18:2689-2699.
50. Chan MY, Ip WY, Choi KC. The effect of a self-efficacy-based educational programme on maternal breast feeding self-efficacy, breast feeding duration and exclusive breast feeding rates: a longitudinal study. Midwifery. 2016;36:92-98.

How to cite this article: Sze KY, Chan ZCY, Chiang VCL. Women's experiences of formula feeding their infants: an interpretative phenomenological study. Frontiers Nurs. 2018; 1: 49-60. https://doi.org/10.1515/fon-2018-0008 